\title{
Male Involvement in Maternal Health Planning Key to Utilization of Skilled Birth Services in Malindi Subcounty, Kenya
}

\author{
Lilian Nyamusi Nyandieka, ${ }^{1,2}$ Mercy Karimi Njeru, ${ }^{1}$ Zipporah Ng'ang'a, ${ }^{2}$ \\ Elizabeth Echoka, ${ }^{1}$ and Yeri Kombe ${ }^{1}$ \\ ${ }^{1}$ Centre for Public Health Research, Kenya Medical Research Institute (KEMRI), P.O. Box 20752, Nairobi 00202, Kenya \\ ${ }^{2}$ Institute of Tropical Medicine and Infectious Diseases, Department of Public Health, Jomo Kenyatta University of \\ Agriculture and Technology, P.O. Box 62000, Nairobi 00200, Kenya \\ Correspondence should be addressed to Lilian Nyamusi Nyandieka; nyandieka.n@gmail.com
}

Received 20 November 2015; Accepted 21 January 2016

Academic Editor: Ronald J. Prineas

Copyright @ 2016 Lilian Nyamusi Nyandieka et al. This is an open access article distributed under the Creative Commons Attribution License, which permits unrestricted use, distribution, and reproduction in any medium, provided the original work is properly cited.

\begin{abstract}
Background. In Malindi, rural populations face challenges in accessing skilled birth services. Consequently, the majority of women deliver at home and only seek help when they have complications. This paper reports part findings from a study conducted to assess health priority setting process and its implication on availability, access, and use of emergency obstetric care services in Malindi. Methods. The study utilized qualitative methods to collect data from health personnel and maternal health stakeholders including community members. Source and method triangulation was used to strengthen the credibility of study findings. Data was categorized manually into themes around issues relating to utilization of skilled birth services discussed in this paper. Findings. Various barriers to utilization of skilled birth services were cited. However, most were linked to mwenye (the husband) who decides on the place of birth for the wife. Conclusion. Husbands are very influential in regard to decisions on skilled birth service utilization in this community. Their lack of involvement in maternal health planning may contribute as a barrier to utilization of skilled care by pregnant women. There is need to address the mwenye factor in an attempt to mitigate some of the barriers cited for nonutilization of skilled birth services.
\end{abstract}

\section{Background}

About 830 women die from pregnancy or childbirth related complications around the world every day. Maternal mortality ratio in developing countries in 2015 was 239 per 100,000 live births versus 12 per 100,000 live births in developed countries. There are large disparities within countries, between women with high and low income and between women living in rural and urban areas [1]. A key component of the strategy to reduce maternal morbidity and mortality has been to increase the utilization of skilled birth attendance and facility-based childbirth. While global skilled birth attendance rates increased by $12 \%$ in developing regions over the past two decades, almost one-third of women in these regions deliver without a skilled birth attendant (SBA) [2].
In many developing countries, the majority of births still occur at home, with the mother being assisted by a family member or traditional birth attendants (TBAs) who are not trained to manage obstetric complications [3]. In Sub-Sahara Africa, there is wide variation in antenatal care (ANC) attendance and women often do not receive the recommended ANC $[4,5]$. Although $71 \%$ of pregnant women attend formal ANC at least once, only $44 \%$ attend ANC four or more times [5]. Pregnant women attend clinics but do not seek skilled birth services when they are due for delivery. Women attend ANC to monitor the progress of their pregnancy, to check the position of the unborn child, to identify problems during pregnancy, and to get the medicines provided during ANC to ensure the health of the pregnancy and the development of the baby. Another reason for attending is that ANC is 
viewed as a normal part of pregnancy and is often considered compulsory, a result of the authority of health staff or the notion of it being the "law." In Kenya, obtaining an ANC (or "birth") card motivates attendance. These cards contain details of ANC attendance without which one can encounter problems should there arise a need to deliver at a health facility, as she can be denied care [6].

Increasing the proportion of women delivering in a health facility is challenging, as it requires comprehensive efforts to overcome sociocultural, economic, geographical, and infrastructural obstacles to reaching facility-based care [7]. Furthermore, it requires effort to improve both the coverage and the quality of care provided to women at health facilities, including women's rights to dignified and respectful care [8]. In Sub-Sahara Africa, women continue to face limited access to services due to lack of decision making authority to seek help [9] as their decision making power regarding reproduction and sexuality is limited [10]. Because patriarchy invests men with the power to determine what their wives can do or not, men often have control over women's access to and utilization of maternal health services [11]. Men have social and economic power and have tremendous control over their partners. They decide the timing and conditions of sexual relations, family size, and whether their spouse will utilize available health care services [12]. Men's knowledge about the importance of maternal health services increases with active participation, which in turn makes them more likely to encourage and support their wives to use them [13-15]. In Kenya, maternal mortality ratio stands at 488 per 100,000 live births, and the proportion of skilled birth attendance remains below 50\% [16]. The government phased out TBA services for pregnant women in favor of skilled care delivery. However, TBAs remain highly utilized by the rural women during pregnancy and childbirth [17].

This paper reports part findings of a study conducted to assess health priority setting process and its implication on availability, access, and use of emergency obstetric care (EmOC) services in Malindi. The paper depicts the role of mwenye in the utilization of skilled birth services.

Mwenye is an acronym originating from the word "mwenyewe," a Kigiriama (local dialect) and Kiswahili word that means owner, in this case the husband. The word mwenye came into usage because for every decision that has to be made by the local women, the word "mwenyewe" has to be invoked. The local women cannot make decisions regarding their health unless mwenye has been consulted. Mwenye has the last say on the place of birth for his wife.

\section{Methods}

2.1. Study Design. This study utilized qualitative methods for data collection. Source and method triangulation was used to strengthen the credibility of study findings. This included indepth interviews (IDIs) and focus group discussions (FGDs) to collect information from the study population.

2.2. Study Area and Setting. This study was conducted in six health facilities in Malindi District (now Malindi Sub-county) in the coastal region of Kenya between November 2012 and April 2013. During the time the study was conducted, the study site comprised Malindi and Magarini, which have since been split into Malindi and Magarini Subcounties. The area had 105 public and private health facilities [18]. Six health facilities from different sites were purposively selected with the assistance of the then District Medical Officer of Health $(\mathrm{DMOH})$. Four were public health facilities (a health centre in level three and three dispensaries in level two). In addition, one faith based facility and one NGO run facility were selected for the study. The six facilities were selected due to the distance between them and the main referral facility in Malindi which pose a challenge in accessing specialized care whenever there is a childbirth complication. Additionally, an NGO run facility within Malindi town was included in the study to share their experiences as stakeholders in maternal health making a total of seven facilities selected.

2.3. Study Population. The study population consisted of in-charges of health facilities, reproductive health services heads, private stakeholders who provide and support maternal health services, and health facility committee members. At the community level, women, married men, TBAs, opinion leaders, and Community Health Workers (CHWs) were included in the study.

2.4. Recruitment. The facility in-charges and heads of reproductive health services were included in the study by virtue of their positions at the facilities as providers of maternal health services. Details of the stakeholders involved with maternal health matters were shared at the district headquarters. The stakeholders and private, faith based, and nongovernmental institutions were included to share their views and experiences on utilization of skilled birth services. Health facility committee members were selected as community representatives and women seeking health services were invited to give their views as end users. TBA group leaders, $\mathrm{CHW}$ and opinion leaders in the area were identified and included in the study to share their experiences on utilization of skilled birth services.

Focus group discussions were organized and held with married men and women in the same age categories and similar education background. The discussions were conducted separately for men and women and were moderated by the principal investigator. The men and women were recruited to share their perspectives as family decision makers and consumers of services, respectively. Additionally, an FGD was conducted with TBAs, who deliver the women at home.

2.5. Ethical Considerations. Approval to conduct this study was granted by the Ethical Review Committee of Kenya Medical Research Institute (Scientific Steering Committee number 2288). The then DMOH Malindi granted permission to conduct the study at the health facilities. Informed consent was sought from individual participants.

2.6. Data Collection and Storage. Data was collected using audio-recorders. Permission to record the interviews and 
FGDs was sought from the study participants. In total, 22 IDIs and seven FGDs were conducted. IDIs were conducted with facility in-charges, reproductive health services heads, stakeholders, and health facility committee members. Women seeking services at the facilities, TBAs, CHWs, and opinion leaders were also interviewed. Three FGDs were conducted with male members, three with women and one with TBAs.

Interview guides addressed maternal health issues in the district and their local settings, preferred place of delivery for the pregnant women, utilization of skilled birth services, what they do when they have women with delivery complications, and involvement of community members in planning for maternal health services. Questions also included the kind of services offered and any special arrangements in place with the existing public health system in providing maternal health services. Interviews with community members were on their experiences while seeking health services at the facilities and challenges and decision making at the family level to seek health services.

All participants were interviewed by the principal investigator at their respective places of work or at the health facilities in their area. Women were interviewed at the health facilities where they were attending ANC clinics or seeking treatment services. One of the health personnel from an NGO run facility was not available for interviewing due to her busy schedule. Two committee members of the public health facilities were not available, while two women declined to participate because they did not have permission from their husbands. FGDs were held at places that were convenient for the participants. Data collection was concluded when the target population had been covered.

Data from the audio-recorders was backed up in a laptop and external disks. Transcribed data in word format was stored in folders, secured by password, and backed up. Transcribed data was given code numbers for anonymity.

2.7. Data Analysis. Data was analyzed thematically. Interviews were transcribed verbatim; and those conducted in Kiswahili were translated into English. This data was then explored to identify important and relevant themes of the study. These were subsequently labeled according to their relevance and a series of categories built up to explain the events that were emerging from the study. This data was categorized manually into themes around the core issues relating to utilization of skilled birth services. Emerging categories were merged to form core categories which are discussed in this paper.

\section{Findings}

The findings reported here are on themes related to home deliveries, the extent of the practice, reasons for nonutilization of skilled birth services, and community participation in maternal health planning.

3.1. Home Deliveries. The majority of the participants reported that most women in the study area deliver at home with TBAs and/or with other relatives. However, a few informants reported that after experiencing loss of their babies due to complications at home, they understood the importance of seeking skilled care during delivery. After their losses, they started utilizing skilled care during delivery.

I see that the women in the village like to try to deliver at home first, then when things don't go as expected, they start looking for ways to get to the facility (male FGD participant, facility 5).

During delivery they have decided they will deliver at home assisted by the TBA or by the mother in law, then when they get complications is when they come to the facility (Reproductive Health Services Head, facility 6).

I attend clinic; but I have delivered all my seven children at home. But then I experienced a problem with my eighth born. When I came to the health facility, I was told that if I had come earlier they would have established the condition of the baby, but it was too late. The baby came out when it was already dead. So recently I got pregnant again. That is why I am here. And I intend to deliver at the health facility when the time comes (pregnant woman, facility 2).

Once my wife also went to the TBAs for the massage and when the time for delivery came, we were forced to take her to the facility because she was unable to deliver with the TBA. ... the doctor asked her to push, and it was not possible. She continued trying and eventually the doctor realized that the baby was dead. After this experience when she got pregnant again, I told her not to go to the TBAs so that we could observe the difference. So when the time for delivery came, I brought her to the facility and she delivered the baby without much problem (male FGD participant, facility 1).

3.2. Extent of the Home Delivery Practice. The majority of the participants, including the community members, confirmed that most women deliver at home for various reasons. The facility in-charges reported that they easily lose mothers because they do not seek services at the available health facilities, which can handle all deliveries except when there is a complication that requires a referral to the district hospital.

In maternal mortality we (Malindi) are at around 600 per 100,000 live births; and at the national level it is around 488 per 100,000 live births. So ours is higher than the national; and the major cause is home deliveries. We are delivering more mothers at home here assisted by TBAs; so they end up with post-partum hemorrhage or sometimes they have other complications like high blood pressure, which actually if they come to the hospital can be controlled (Reproductive Health Services Head, facility 6). 
We used to have a single mother coming for delivery (per month) and it's because they had some complication back at home. But nowadays we get ten, eleven, twelve per month; of which is still low. Because you can get up to fifty (50) newborn babies being brought for BCG (vaccination). And you deliver nine or ten; in a nutshell, that's a drop in the ocean (in-charge, facility 1).

They never come to deliver as we expect, we usually get 180-200 delivering mothers within a month bringing babies for vaccination. But those who deliver here (facility) are like 19-20 per month (in-charge, facility 5).

3.3. Reasons for Nonutilization of Skilled Birth Services. Various reasons were cited for nonutilization of skilled birth services, most of which could be observed on the ground. The state of health facilities, with inadequate space and personnel, distance to the facilities, costs involved, unpreparedness, and lack of decision making authority were the main reasons why the women did not seek skilled birth services.

3.3.1. The State of Health Facilities. This involved situations where there was no suitable provision for labor and delivery rooms in some of the facilities visited. In such cases, the women shared the available space with other patients seeking curative services at the facility, thereby lacking privacy and raising issues of hygiene. It was common for patients to be admitted for observation into space that was reserved as a labor room.

When patients with a wound to be dressed come, they are taken inside for cleaning and dressing as the woman labors in the same room. Therefore, it becomes difficult for the husbands to allow their wives to come to the facility when they know that they do not have privacy (male FGD participant, facility 2).

And the other reason is that when the wounds are being dressed there and by the same person that is going to deliver them, they are uncomfortable because they do not know what the wound is all about, so they fear infection for the new born (male FGD participant, facility 2).

3.3.2. Inadequate Resources. The inadequate resources are in terms of personnel and supplies. Most of the facilities visited operate with one health employee, who in some instances is required to be at the district headquarters for meetings and trainings or for some other reason, thereby leaving the health facilities unattended to or attended to by unqualified staff. There were shortages of basic supplies such as gloves and disinfectant, making it difficult to render services to those who need them.

Understaffing is a major challenge. And that's not just us, but the entire Malindi district. Most of the facilities have like one or two staff (in-charge
facility 1).

There is only one nurse here who is responsible for day and night. And there are patients all the time (male FGD participant, facility 1).

And sometimes you find that they do not even have gloves (male FGD participant, facility 2).

3.3.3. Distance to the Health Facilities. The health facilities in rural Malindi are unevenly distributed resulting in some users traveling long distances to seek services. However, there are those who live near the facility but still deliver at home for other reasons.

Sometimes there are problems because of the distance. ... In my opinion, the facilities should be increased and the existing ones improved (committee representative 2 ).

... the distance to the facility, there are people who come almost $20 \mathrm{~km}$ from here (in-charge facility 2).

3.3.4. Costs. These include the cost of travel to the facility and delivery fees usually paid at the health facility. Maternity services are supposedly free in public facilities, especially dispensaries and health centres. However, due to supplies shortage, the women are charged a standard fee which takes care of the basic necessities. If the woman is taken to the health facility by a TBA because she was unable to deliver at home, the TBA is paid a small sum as a token of appreciation for bringing in the woman. As most of the women in this locality are stay-home mothers, the husbands have to meet all the costs. So if mwenye does not have the money, or something to sell, then the woman will have to deliver at home.

'Mwenye is not around and has to come and give fare to go to the facility' the women say (Reproductive Health Services Head, facility 6).

If Mwenye is not financially good; he may refuse to give approval for the woman to seek services at the health facility (Head, Maternal Health programme (stakeholder)).

3.3.5. Lack of Birth Preparedness. Many couples do not have a birth plan for the baby and panic when the labor pains come; like it is an emergency. When the time for delivery comes, they are found completely unprepared, with no money put aside for any eventuality, from fare to delivery fee.

Anyway, that is how the mothers are. They wait until they are in labor; they behave as if they didn't know they were expecting a baby. They are so unprepared for the baby. The fathers go looking for so and so to borrow money and if they bounce, the woman is still in pain and eventually delivers at home. Preparing for the baby is a big problem (Community Health Worker, facility 1). 
Our husbands do not prepare for the arrival of the baby. So when a woman goes into labor and there are complications, everyone gets confused (female FGD participant, facility 5).

3.3.6. Decision Making at Family Level. In this community, it is the husbands that make decisions, including where the expectant woman will deliver. Even in a case where a woman has a complication and requires urgent help, the husband has to be the one making that decision, irrespective of whether he is around or not. A programme officer shared an experience where a nurse referred a woman in labor to the referral hospital because she needed specialized care and organized for an ambulance to take her there. The woman refused to get into the ambulance because the husband was not around to give permission for her to go to the referral hospital. The husband was telephoned, and he asked to speak to the wife. He scolded her for wanting to "compel" him to allow her to go to Malindi. The woman walked away and did not get into the ambulance.

In this community the man owns everything; they call this mwenye, so if you listen carefully it's like the decision to go or not to go (to a facility) lies with the mwenye. This business of taking an ambulance should be between 'you and you'. Mwenye has to give permission for the wife to step into the ambulance; now that is if he has goats and chicken at home which she (the wife) takes care of every day; and has no authority to decide to go to the facility to save her life (Head, Maternal Health programme (stakeholder)).

You get someone is in labor and you want to assist her to go to the health centre, and she tells you her husband is not at home. Meaning she cannot leave until the husband comes back. The husband has to give permission, even if on phone (Community Health Worker, facility 5).

Everything it is the man to decide; the owner of that woman is the mwenyewe... so Mwenye doesn't want, or he is not around, or he has to come and make the decision for the woman to be taken to the facility (Reproductive Health Services Head, facility 6).

Male FGD participants accepted the blame for not advising their women and for not putting their foot down when it was time for decision making on where their wives should deliver.

Let us just say that some of us are guilty of not wanting to use the health facility because of previous events.... We only come to realize the importance of the facility when we have a problem (male FGD participant, facility 1).

3.4. Involvement of Community Members in Maternal Health Planning. Participation in health matters is through community representatives who are nominated to the facility committees. However, the majority of the participants reported that they do not know who their committee representatives to the health facility committees are. And that they do not know who selects the representatives to the committees and what criteria is used to select them. They only get to hear that the health facility committee members have been selected.

We do not know any committee representatives. And we also don't know what they discuss when they have meetings (female FGD participant, facility 4).

Maybe the education committee has tried to involve the community members, but not the health facility committee. They do their own things (female FGD participant, facility 5).

We have dispensary committee members. They are the ones who are responsible for presenting our problems and grievances in their sittings ... but they do not have the power to push for action. They can only air them to the person in charge of dispensaries (male FGD participant, facility 2).

\section{Discussion}

This paper depicts the role of mwenye (the husband) in the utilization of skilled birth services in rural Malindi. Findings of this study indicate that the majority of women deliver at home with TBAs or with a relative, usually the mother in law, despite attending ANC clinics. A few informants who had lost their babies due to complications at home recounted their experiences and acknowledged the importance of seeking skilled care during delivery. However, the majority cited different barriers for nonutilization of skilled birth services. On the face of it, all barriers can be observed on the ground. However, a closer look into the barriers indicates that most revolve around mwenye factor.

Although men play a key role in the family as the main decision makers, interventions and programmes to improve utilization of health services usually target women. Little has been done to involve men in maternal health matters. Yet studies have emphasized how men's role can contribute to better outcomes for their pregnant wives [19, 20]. Evidence from diverse settings indicates that women often have only partial, if any, autonomy over their reproductive and sexual health [21-24]. Their position in society is considered inferior and has considerably less power than their male counterpart in making household decisions [25]. Husbands can influence maternal health care utilization by contributing to developing a birth plan [15], a factor which has been shown to be lacking in this study, as most women in Malindi wait upon their husbands to cater for all their financial needs because they have no means of their own to plan for the unborn child.

Men play a vital role in the safety of their female partners' pregnancy and childbirth [12] especially due to their economic dominance and decision making power. It has been shown that some women's access and utilization of Maternal and Child Health (MCH) services depends upon their partners [26]. For men to make the right decision for their wives regarding place of delivery and professional attention, 
they need to understand the importance of maternal health care utilization [27]. There is therefore a need to strategize on how to have men participate in designing and planning for maternal health services at the level of need, the community level. If men understand their role in maternal health services utilization, they are likely to ease some of the barriers cited in this study by responding to the needs of their pregnant women.

Reforms in the health sector of many countries have been ongoing and have been associated with critical debates on who should take an active part in making informed decisions regarding setting priorities related to resource allocation and service delivery. Of the issues usually discussed critically is how to involve local communities in the reform processes and the role of professionals in which case controversy arises when some observers find the professionals downgrading others considered to be lay persons in the priority-setting process [28]. Calls for meaningful multisectoral partnerships with communities recognize that collaboration is central to ensure acceptable, appropriate, and effective responses to begin to tackle entrenched rural inequities [29]. Harnessing community capacity is integral to developing locally responsive health services [30] and is in the interest of communities and government as it draws together rural social capital, maximizes the innate, adaptive, inventive, and innovative nature of rural people [31], and leads to empowered communities capable of developing local solutions [32].

Ministry of Health $(\mathrm{MoH})$ guidelines for health management committees [33] provide for participation in health planning process through representation of community members in order for them to represent community interests. The said representation has been found to be inadequate, as perceived by some of the in-charges of health facilities in Malindi [34]. Besides most community members do not know their representatives and do not discuss their needs before the representatives attend meetings to represent them. It is probable that the community maybe more receptive to health services where they have been involved in some way. A study conducted in Malawi found that a requirement for men to accompany their wives to the health facilities in order for the women to get services was perceived as punitive as community was not consulted on the decision but were just informed and had no power to question the authority [35]. As literature has portrayed men as reluctant users of health care [36], getting men to participate in maternal health care which is dominated by women could be even harder. There is, therefore, the need to strategize on how to sufficiently involve community members and specifically men in maternal health services as it entails social and behavior change. In Malindi, male involvement was identified as one of the strategies to improve maternal health service utilization. However, no strategies were put in place to specifically target men. One strategy suggested in the annual operations plan (AOP) [37] was to sensitize community through barazas, a strategy that is usually carried out by calling community meetings under the local administration to address emerging issues in the community. One of the weaknesses of this strategy is that usually the men send their wives to such meetings to represent them [34], thus leaving out the very people targeted by the health planners.

The barriers cited for nonutilization of skilled birth services in this study area can broadly be grouped into two categories, those entrenched in the health system, for example, the deplorable state of health facilities, long distances to the facilities, inadequate personnel, and lack of supplies. Other barriers are those that directly touch on the consumers, for example, costs involved in seeking skilled care, unpreparedness for the unborn child, and lack of decision making authority. While the consumers may not have a solution to barriers entrenched in the health system, they can certainly attempt to tackle the barriers that touch on them as users. An attempt can be made to resolve some of the barriers by involving men. In the case of costs involved, husbands should be appropriately involved to understand maternal health issues, in order for them to initiate saving plans with their wives for the unborn baby or identify any other source of funds like something to sell when the baby arrives. This will take care of unpreparedness which has been reported in this study. Unevenly distributed facilities, poor road network with resultant long distances, and lack of public transport have been identified as a problem in the area. The alternative transport which is motor bikes has been characterized as uncomfortable especially when the women are in labor. If from the onset a man decides that his wife will deliver at the health facility, then as soon as labor starts the woman can organize to go to the health facility, affording the family time to organize travel means of their choice, to alternatively travel on the motorbike, which may be less uncomfortable in the initial stage of labor. Regarding lack of decision making power among women, if men are appropriately involved in maternal health issues and understand the need to utilize skilled birth services, should labor start in their absence, the women can go ahead to the facility and the husbands can follow. This will be possible because the couples already have a saving plan for the arrival of the baby.

It is also probable that once the male members of the community are involved, they can demand that the available facilities be improved to a standard that they are comfortable with for their spouses to use. Alternatively, if the facilities are utilized to the maximum, the system may see the need to improve on the facilities, and even involve the community members in the improvements as communities in this area have contributed in the past in health facility infrustructure development and improvement.

4.1. Study Stength. This study was conducted at the first point of contact for the service consumers and health providers, therefore giving a clear reflection of what happens at the point of need. It is highly probable that the current findings apply more widely than Malindi Subcounty and that they are vital in providing the newly created county governments in Kenya with findings that might directly affect them.

4.2. Study Limitation. Most clients were interviewed at the health facilities within their area, which is not a neutral 
ground to conduct interviews on health matters as this could influence the responses of the interviewees.

\section{Conclusion}

Husbands are very influential in regard to decisions on skilled birth service utilization in this community. Their lack of involvement in maternal health planning may contribute as a barrier to utilization of skilled care by pregnant women. There is a need to address the mwenye factor in an attempt to mitigate some of the barriers cited for nonutilization of skilled birth services. This can be done by intensively involving the community members and particularly husbands in maternal health planning at the various levels, beginning from the community level (level one) to the subcounty planning forums.

\section{Conflict of Interests}

The authors declare that there is no conflict of interests regarding the publication of this paper.

\section{Authors' Contribution}

Lilian Nyamusi Nyandieka developed the concept, participated in data collection and analysis, and initiated the paper. Mercy Karimi Njeru was involved in data analysis and critically reviewed the paper. Yeri Kombe participated in concept development and critically reviewed the paper. Zipporah Ng'ang'a participated in concept development and reviewed the paper. Elizabeth Echoka critically reviewed the paper. All authors read and approved the final paper.

\section{Acknowledgments}

This study received part financial support for data collection from Centre for Health Research and Development, Faculty of Health and Medical Sciences, University of Copenhagen, facilitated by Jens Byskov. All the health personnel, stakeholders, partners and community members who willingly participated in this study are hereby acknowledged. Special appreciation to the DMOH's office, Malindi for permission to carry out this research at the health facilities; and the Director, KEMRI for permission to carry out this study.

\section{References}

[1] World Health Organization (WHO), "Trends in maternal mortality: 1990 to 2015: estimates by WHO, UNICEF, UNFPA, World Bank Group and the United Nations Population Division," http://www.who.int/reproductivehealth/publications/ monitoring/maternal-mortality-2015/en/.

[2] United Nations, The Millennium Development Goals Report 2014, United Nations, New York, NY, USA, 2014.

[3] M. A. Koblinsky, O. Campbell, and J. Heichelheim, "Organizing delivery care: what works for safe motherhood?" Bulletin of the World Health Organization, vol. 77, no. 5, pp. 399-406, 1999.

[4] C. Abou-Zahr and T. Wardlaw, Antenatal Care in Developing Countries: Promises, Achievements and Missed Opportunities:
An Analysis of Trends, Levels and Differentials, 1990-2001, World Health Organization, Geneva, Switzerland, 2003.

[5] M. V. Kinney, K. J. Kerber, R. E. Black et al., "Sub-Saharan Africa's mothers, newborns, and children: where and why do they die?" PLoS Medicine, vol. 7, no. 6, Article ID e1000294, 2010.

[6] C. Pell, A. Meñaca, F. Were et al., "Factors affecting antenatal care attendance: results from qualitative studies in Ghana, Kenya and Malawi," PLoS ONE, vol. 8, no. 1, Article ID e53747, 2013.

[7] M. A. Bohren, E. C. Hunter, H. M. Munthe-Kaas, J. P. Souza, J. P. Vogel, and A. M. Gülmezoglu, "Facilitators and barriers to facility-based delivery in low- and middle-income countries: a qualitative evidence synthesis," Reproductive Health, vol. 11, article 71, 2014.

[8] World Health Organization, WHO Statement: The Prevention and Elimination of Disrespect and Abuse During Facility-Based Childbirth, World Health Organization, Geneva, Switzerland, 2014.

[9] H. Essendi, S. Mills, and J.-C. Fotso, "Barriers to formal emergency obstetric care services' utilization," Journal of Urban Health, vol. 88, supplement 2, pp. 356-369, 2011.

[10] World Health Organization (WHO), Improved Access to Maternal Health Services, World Health Organization (WHO), Geneva, Switzerland, 1998.

[11] C. E. Bird and P. P. Rieker, "Gender matters: an integrated model for understanding men's and women's health," Social Science and Medicine, vol. 48, no. 6, pp. 745-755, 1999.

[12] Z. Iliyasu, I. S. Abubakar, H. S. Galadanci, and M. H. Aliyu, "Birth preparedness, complication readiness and fathers' participation in maternity care in a northern Nigerian community," African Journal of Reproductive Health, vol. 14, no. 1, pp. 21-32, 2010.

[13] A. Ahmed, S. A. S. Hossain, A. Quaiyum, L. Reichenbach, A. A. Mamun, and N. L. Huq, "Husbands' knowledge on maternal health care in rural Bangladesh: an untapped resource?" Tropical Medicine \& International Health, vol. 16, p. 291, 2011.

[14] M. Ali, H. Rizwan, and H. Ushijima, "Men and reproductive health in rural Pakistan: the case for increased male participation," European Journal of Contraception and Reproductive Health Care, vol. 9, no. 4, pp. 260-266, 2004.

[15] O. Kakaire, D. K. Kaye, and M. O. Osinde, "Male involvement in birth preparedness and complication readiness for emergency obstetric referrals in rural Uganda," Reproductive Health, vol. 8, article 12, 2011.

[16] Kenya National Bureau of Statistics (KNBS) and ICF Macro, Kenya Demographic and Health Survey 2008-09, KNBS, ICF Macro, Calverton, Md, USA, 2010.

[17] E. Echoka, A. Makokha, D. Dubourg, Y. Kombe, L. Nyandieka, and J. Byskov, "Barriers to emergency obstetric care services: accounts of survivors of life threatening obstetric complications in Malindi District, Kenya," The Pan African Medical Journal, vol. 17, supplement 1, p. 4, 2014.

[18] Ministry of Public Health and Sanitation, "Kenya Master Health Facility List," 2010, http://www.ehealth.or.ke/facilities/ latestfacilities.aspx.

[19] M. Drennan, “New perspectives on men's participation,” Population Reports, Series J 46, Johns Hopkins University, School of Public Health, Population Information Program, Baltimore, Md, USA, 1998, https://www.k4health.org/sites/default/ files/j46.pdf. 
[20] United Nations Population Fund (UNFPA), Family Planning in Kenya: Not for Women Only, United Nations, New York, NY, USA, 2009, http://www.unfpa.org/public/News/pid/3015.

[21] S. Castle, M. K. Konaté, P. R. Ulin, and S. Martin, "A qualitative study of clandestine contraceptive use in urban Mali," Studies in Family Planning, vol. 30, no. 3, pp. 231-248, 1999.

[22] J. Pulerwitz, S. L. Gortmaker, and W. DeJong, "Measuring sexual relationship power in HIV/STD research," Sex Roles, vol. 42, no. 7-8, pp. 637-660, 2000.

[23] Y. M. Adamu and H. M. Salihu, "Barriers to the use of antenatal and obstetric care services in rural Kano, Nigeria," Journal of Obstetrics and Gynaecology, vol. 22, no. 6, pp. 600-603, 2002.

[24] A. J. Gage, "Barriers to the utilization of maternal health care in rural Mali," Social Science and Medicine, vol. 65, no. 8, pp. 16661682, 2007.

[25] S. P. Morgan and B. B. Niraula, "Gender inequality and fertility in two Nepali villages," Population and Development Review, vol. 21, no. 3, pp. 541-561, 1995.

[26] M. R. Dudgeon and M. C. Inhorn, "Men's influences on women's reproductive health: medical anthropological perspectives," Social Science and Medicine, vol. 59, no. 7, pp. 1379-1395, 2004.

[27] B. C. Mullany, S. Becker, and M. J. Hindin, "The impact of including husbands in antenatal health education services on maternal health practices in urban Nepal: results from a randomized controlled trial," Health Education Research, vol. 22, no. 2, pp. 166-176, 2007.

[28] G. Southon and J. Braithwaite, "The end of professionalism?" Social Science and Medicine, vol. 46, no. 1, pp. 23-28, 1998.

[29] J. Farmer, L. Philip, G. King, J. Farrington, and M. Macleod, "Territorial tensions: misaligned management and community perspectives on health services for older people in remote rural areas," Health \& Place, vol. 16, no. 2, pp. 275-283, 2010.

[30] J. Kulig and A. Williams, Health in Rural Canada, UBC Press, Vancouver, Canada, 2012.

[31] Commonwealth of Australia, National Strategic Framework for Rural and Remote Health, Canberra, Australia, 2012.

[32] S. Kilpatrick, "Multi-level rural community engagement in health," Australian Journal of Rural Health, vol. 17, no. 1, pp. 3944, 2009.

[33] Ministry of Health (MOH), Guidelines for District Health Management Boards, Hospital Management Boards, and Health Center Management Committees, Ministry of Health (MOH), Nairobi, Kenya, 2002.

[34] L. N. Nyandieka, Y. Kombe, Z. Ng'ang'a, J. Byskov, and M. K. Njeru, "An assessment of priority setting process and its implication on availability of emergency obstetric care services in Malindi District, Kenya," The Pan African Medical Journal, vol. 22, article 156, 2015.

[35] L. I. Kululanga, J. Sundby, A. Malata, and E. Chirwa, "Male involvement in maternity health care in Malawi," African Journal of Reproductive Health, vol. 16, no. 1, pp. 145-157, 2012.

[36] D. Wilkins, “'Getting It Sorted': identifying and implementing practical solutions to men's health," Journal of Men's Health and Gender, vol. 2, no. 1, pp. 13-16, 2005.

[37] Republic of Kenya, District Health Sector Plan, 2009/2010. Malindi District Annual Operational Plan 5. 2009. 


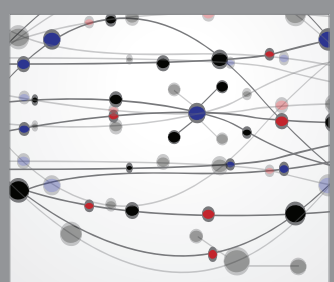

The Scientific World Journal
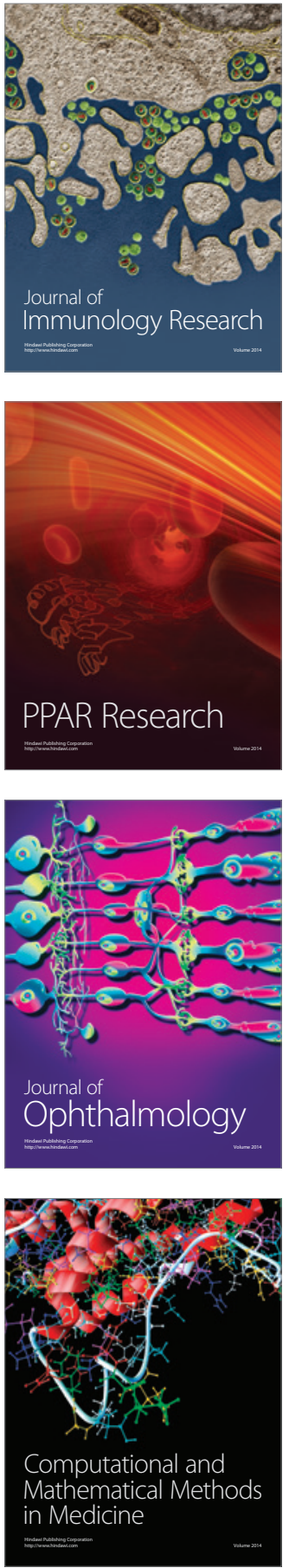

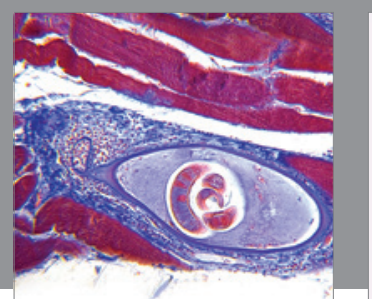

Gastroenterology Research and Practice

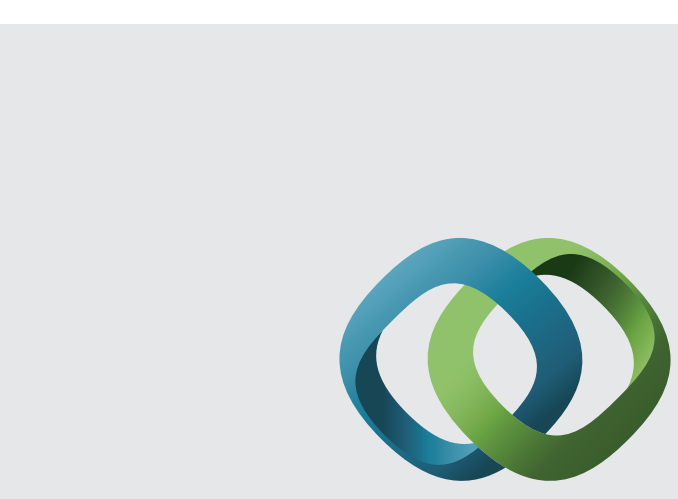

\section{Hindawi}

Submit your manuscripts at

http://www.hindawi.com
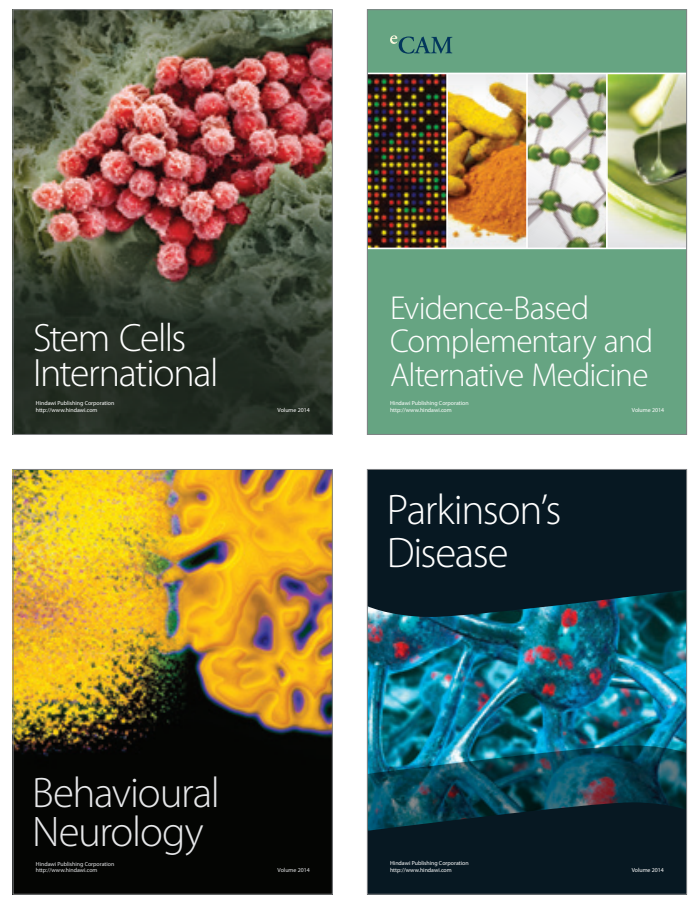
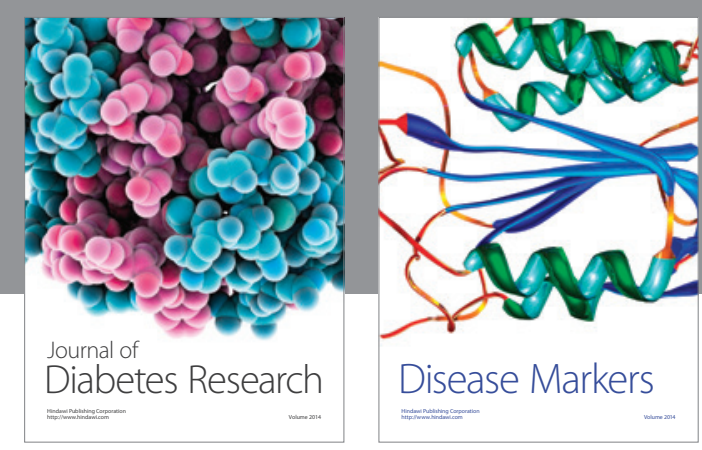

Disease Markers
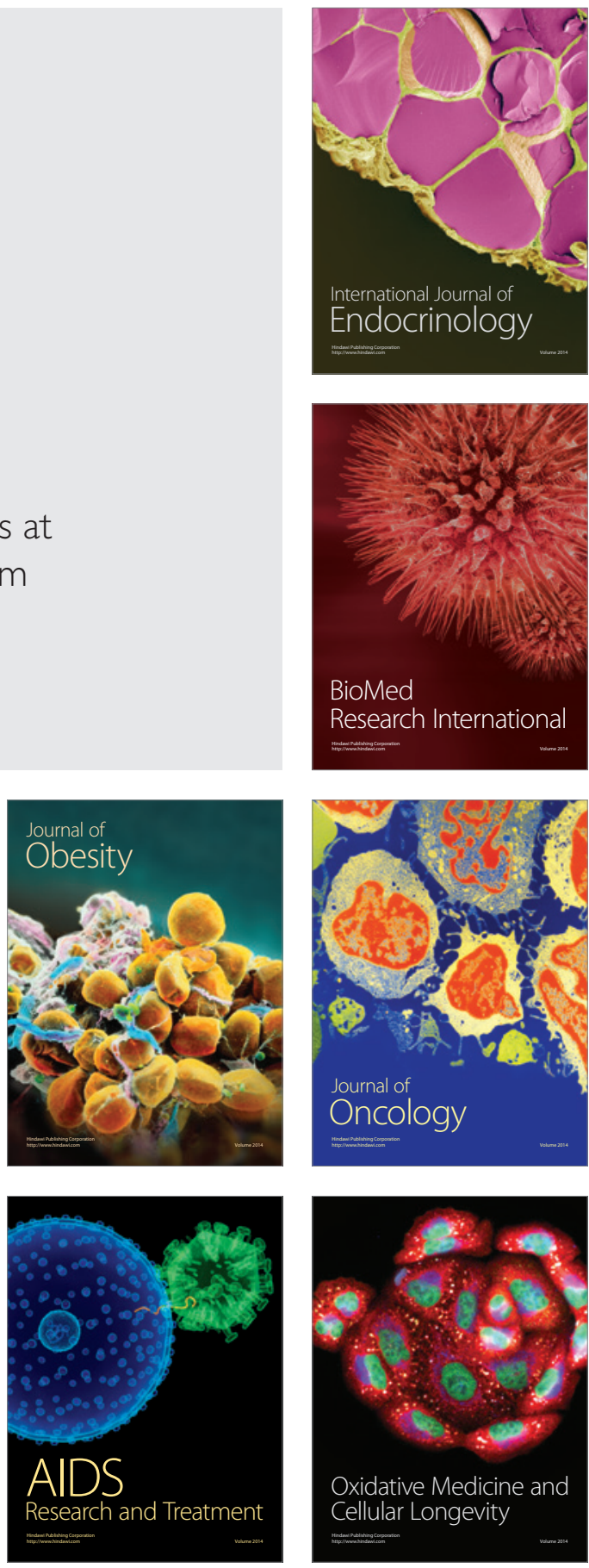